\title{
A FRAMEWORK TO ENHANCE THE PRACTICE OF MAINTENANCE BUDGETING IN COMMERCIAL BUILDINGS IN SRI LANKA
}

\author{
RUKANYA. S1, SRIDARRAN. P² \& MAHEDRARAJH. G \\ 1,2,3 university of Moratuwa, Colombo, Sri Lanka \\ 1rukanyasenan@gmail.com, 2'gowsigam@uom.lk
}

\begin{abstract}
Inadequate budget control is one of the major challenges that adversely affect the maintenance of a building. The cost of plant asset maintenance of the commercial building is a larger proportion of the overall cost of operation. It is important to allocate financial resources appropriately so that, before serious damage occurs, maintenance measures can be taken. Accordingly, a well-defined maintenance budget (MB) makes it possible to recognise opportunities for creating continuous business performance improvements within the financial constraints of a company. Although required building maintenance can be carried out successfully with an adequate budget, the budget is not well defined in current industrial practice and Sri Lanka is most likely dealing with the same problem. Thus, this study aimed to develop a framework to enhance the practice of a well-defined MB for commercial buildings in Sri Lanka. The qualitative approach was adopted to address this study. A comprehensive literature review was done and five case studies were performed using ten semi-structured interviews to collect the primary data. The interviewees were selected based on their knowledge in the field of maintenance cost planning. Data were analysed through content analysis using both manual and NVivo 12 software. The research finding revealed that prime barriers of prepare an accurate MB are poor planning of maintenance work and resources, faulty maintenance, changes in country market condition, and poor financial support. The key strategies to overcome the barriers are to select the right budget method, arise awareness of top management about building maintenance and avoid faulty maintenance.
\end{abstract}

Keywords: Maintenance budgeting, Commercial buildings, Barriers, Strategies, Sri Lanka

\section{Introduction}

Buildings with state-of-the-art design and construction would not be able to function as planned if not run and maintained properly (Lai, 2010). Maintenance is required to retain the initial performance capacity of a building over its life cycle (Straub, 2012). However, the building maintenance cost is a large proportion of the overall cost of building operation (Ihsan and Alshibani, 2018). Construction activities represent almost $50 \%$ of the total turnover, at the same time building maintenance is one of the larger investments of organisations in the world (Zakiyudin et al., 2019). Booty (2009) stated that more than $90 \%$ of the life cycle of building projects needs maintenance after construction is finished. Further, the author stated that approximately $75 \%$ of a building's overall life cycle cost is attributable to maintenance. The cost of the operation, maintenance, and life cycle ranged from 35 to 41\%, 26 to 30\%, and 6 to $18 \%$ respectively (Weerasinghe, Ramachandra and Rotimi, 2016). Thus, to attain the greatest value for the money, financial management is one of the most important features of maintenance management (Ojua, 2016). Maintenance budgeting plays a vital role to maintain the value of the building effectively (Lennerts and Bahr, 2008). To have an appropriate operation and $\mathrm{MB}$, the responsible authority must properly organise, test, and accept the assessment of the required resources (Lai, 2010). Chen and Tang (2019) indicated that the MB needs to recognise the cost of maintenance financing in buildings to fulfill the maintenance needs adequately and effectively. In this process, the MB is a leading parameter and that needs a proper assessment ahead of the annual maintenance period (Gupta, Gupta and Gandhi, 2014). Thus, it should be prepared as more critical 
than maintenance costs because if incorrectly calculated, it can produce inappropriate benchmarking criteria, so that a reasonable estimation is required for the MB (Muchiri et al., 2011).

In recent, buildings are recognised that maintenance is adversely affected due to inadequate funding and that can lead to increased safety risks, poor public service, higher potential costs, and inefficient activity (Ekim and Ekim, 2016). To evident, Lai (2010) indicated that it is hard to imagine how buildings could sustain without sufficient budgets for their operation and maintenance, though it has quality construction. Further, the author reported that the use of traditional budgeting prevailed at $92 \%$, the application of activity-based budgeting represented a distant second at $44 \%$, and that both expenditure or revenue-based and zero-based budgeting approaches were used only in $8 \%$ of the contracts sampled. Therefore, historical-based budgeting practice predominates between a variety of budgeting bases. Similarly, Bernama (2019) specified that due to inadequate allocations, there has been a backlog of maintenance work. In addition, in the Sri Lankan context, inadequate budgetary control is one of the maintenance factors that affect the organisation's operational and maintenance (Perera et al., 2016). Therefore, a budget is a measurable tool to express the projected costs and resources correctly over a while and thus facilitates are successfully preparing and monitoring their activities (Chartered Institute of Management Accountants (CIMA), 2008).

The efficiency of maintenance activities is influenced by the amount of budget allocated for each task (Che-Ghani, Myeda and Ali, 2016). The allocation of the MB with the statement during the process of formulating the maintenance funding recognises a common problem (Lee and Scott, 2008). It is proof that the annual expense of all maintenance activities will increase the annual budget, and so the decisionmakers have to determine which tasks should take priority this year to maintain the building within the available funds and what should be deferred for the following year (NSW Heritage Office, 2014). Le, Domingo, Rasheed and Park (2018) stated that lack of the data available is known to be a cause for the prevention of effectiveness. Further authors indicated that cost estimation methods for various forms of maintenance have not yet been established due to the lack of a reliable data system. There are currently no realistic techniques for estimating and budgeting the cost of potential maintenance expenses (Bahr et al.,2008). To enhance the practice of a well-defined MB, this research is focused on developing a framework through appropriate budget practice. Therefore, this research is essential and valuable for every commercial building to obtain an idea about the well-defined framework for MB.

Hens, this research aims to develop a framework to enhance the practice of a well-defined MB for commercial buildings in Sri Lanka. The structure of the paper starts with a review of literature relevant to the key concepts of the study. It then outlines the method carried out to achieve the aim of the study and then includes the discussion and recommendations on the research findings.

\section{Literature review}

The literature findings on overview of maintenance and maintenance expenditure, different types of maintenance strategies, different budgeting approaches, and finally barriers of MB practice and some strategies were reviewed.

\subsection{OVERVIEW OF MAINTENANCE}

In British Standards (BS EN 13306) (2017), maintenance is described as a combination of all technical, administrative, and managerial actions during the life cycle of an item intended to retain it, or restore it to, a state in which it can perform the required function. According to Nuratirah, Nasir and Aziz (2018), good maintenance of the building can help to retain the properties which imply various business opportunities available on the track. Conversely, poor and insufficient maintenance of buildings would likely cause more harm and expensive repair work if left unattended (Suffian, 2013). Thus, effective maintenance will help businesses prevent unnecessary outages, maintaining smooth running with no setbacks (Straub, 2012). Reducing the expense of building maintenance will be accomplished with a deep understanding of the expense concepts of building maintenance (Faremi, Adenuga and John, 2014). Therefore, the calculation of the costs associated with system maintenance is important for system designers and cost analysts (Sharma, Kumar and Jain, 2002). Maintenance and operating costs consist of the costs of routine statutory assessments, costs of repairing deteriorated components and elements, costs of periodic activities and repairs, costs of reactive maintenance, and operating costs (Krstic \& Marenjak, 2017). In general, the actual cost of maintenance depends on the quality and usage of the machinery, how much maintenance it requires, and the policy of maintenance and the management strategy (Sondalini, 2000). 


\subsection{MAINTENANCE STRATEGIES}

In BS 8210 (2012), maintenance of any system is subdivided into two major categories planned maintenance and unplanned maintenance. However, unplanned maintenance is needed when a component or subsystem fails at random and this requires a higher downtime due to a lack of availability of resources (savings, qualified staff, special equipment, maintenance facilities), resulting in a logistic delay (Chitra, 2003). According to the BS EN 13306:2017, maintenance is divided into two primary groups, preventive and corrective. Preventive maintenance is further broken down into two major categories: periodic maintenance and condition-based maintenance that shown in Figure 1.

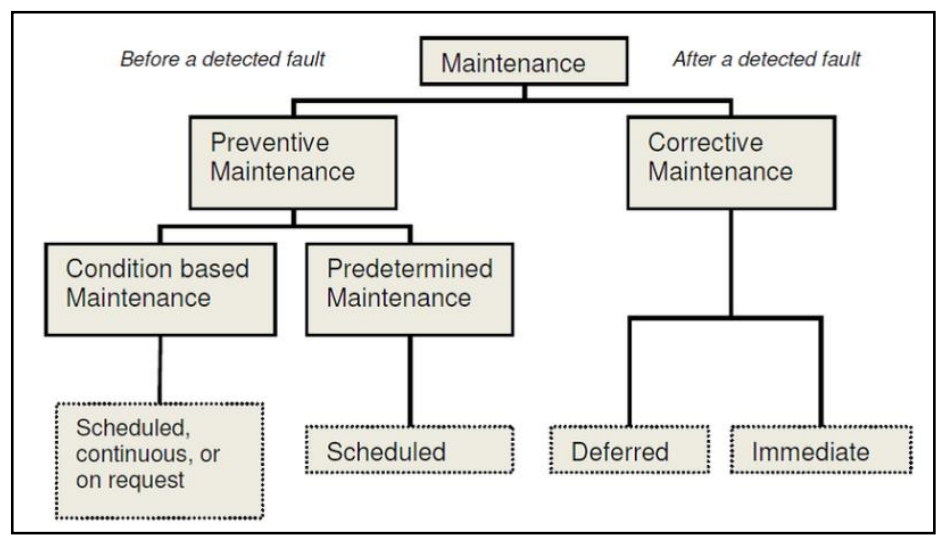

Figure 1 Types of maintenance Source: (BS EN 13306, 2017)

Preventive maintenance (PM) is all activities performed on a scheduled, regular, and precise schedule to maintain an item or equipment in specified working conditions through the checking and reconditioning phase (Dhillon, 2002). It may seem unnecessary as PM does not reflect costs of downtime or output downtime immediately (Lind and Muyingo, 2012). Further, PM has been classified into two categories, condition-based and pre-determined maintenance, in the EN 13306 European Standard (CEN (European Committee for Standardization) EN 13306, 2001). Pre-determined maintenance is PM carried out in compliance with the period or number of units of use intervals identified but without previous condition investigation (Wickern, 2019). PM, which involves a combination of condition monitoring and or inspection and or testing, review, and future maintenance behaviour, is condition-based maintenance (Velmurugan and Dhingra, 2015). Hence, $1 \mathrm{t}$ is important to develop a combination of different maintenance strategies to properly maintain the systems and to ensure that they remain in order and minimise asset downtime and repair costs while maintaining a safe environment for personnel (CEN-European Committee for Standardization, 2001). The cost of maintenance is intimately connected to the maintenance strategy. The cost and cost structure of the following maintenance services are heavily influenced by the maintenance strategy chosen (Schuh, Jussen and Optehostert, 2019). The author further stated that a reactive and failure-related maintenance approach saves spare part costs by maximizing the component's wear stock, while also incurring high machine failure costs owing to unplanned machine downtimes. Preventative replacement of a spare part as part of a preventive maintenance approach improves spare part costs while simultaneously increasing system availability.

\subsection{BUDGETING METHODS}

The use of traditional budgeting prevailed at $92 \%$, the application of activity-based budgeting represented a distant second at $44 \%$, and that both expenditure or revenue-based and zero-based budgeting approaches were used only in $8 \%$ of the contracts sampled (Lai, 2010). Therefore, historical-based budgeting practice predominates between a variety of budgeting bases. Although there are several reasons why companies have different methods to implement a $\mathrm{MB}$, an organization has a significant impact on how well developed and successful these efforts are, either positively or negatively (McNair, 2011). Further, to achieve effective maintenance, budgets should be defined through type and the maintenance strategy should be implemented (Mohd-Noor et al., 2011). Further, there are many ways of budgeting as there are organisations in the world, but the two main approaches include setting the budget from a defined upper limit (top-down) or building up the budget from the ground up based on the need (bottom-up) (Steiner and Kaiser, 2016).

\subsection{BARRIERS AND STRATEGIES}

Barriers to the preparation of an accurate MB were defined under major variables, they are technical factors, managerial factors, financial factors, environmental factors, and social factors. According to Ihsan 
(2017), design problems, faulty maintenance, building characteristics, poor Quality Control, Life cycle cost techniques, low concern for future maintenance, and failure in identifying the true cause of defect were identified as technical factors. The managerial role in most commercial buildings includes organising, controlling, planning and staffing and these components are important in the performance of maintenance work and thus affect the building's maintenance costs (Schuh, Jussen and Optehostert, 2019). Further, the author identified resource management problems, equipment, labor, the unavailability of skilled laborers, faulty workmanship in the initial construction, and uneducated labours as the managerial factors that affect the maintenance spending of an organisation. Due to a lack of scientific procedures for evaluating the budget, subjective and erroneous allocations have resulted in waste or a shortage of resources (Srivastava, Kumar and Gupta, 2020). According to Ihsan (2017), inadequate finance and poor financial control when executing maintenance work were identified as financial factors that affect the cost of maintenance. New maintenance techniques, unqualified and unavailable maintenance contractors, insufficient standards and specifications, and harsh climatic conditions were identified as different environmental factors. Postponements in problems reporting, awareness of the user; and accessibility to the property were identified as social barriers that affect the accuracy of the MB. Select an appropriate budget method, adapt with a combination of different maintenance strategies, quality control, and maintaining the documents are the strategies that help to overcome the barriers (Lai, 2010; Mohd-Noor et al., 2011; Ihsan, 2017). Thus, a lack of an adequate MB might stifle maintenance efforts. On the one hand, having an excess budget might lead to unnecessary spending; on the other hand, a lack of financial resources can result in production outages and harmful plant procedures. As a result, estimating an appropriate MB is crucial for firms to preserve their viability (Srivastava, Kumar and Gupta, 2020).

\section{Research methodology}

The research aims to develop a framework to enhance the practice of a well-defined MB for commercial buildings in Sri Lanka. To achieve the aim, the qualitative method was planned to conduct the research. The research involved defines an appropriate MB via selecting the right budget method and strategies and identifying key considerations. In addition, the attitudes and opinions of the respondents and further detailed explanations of professionals for the enhancement of a well-defined MB need to be explored to achieve the aim of this study. The case analysis can be conducted by a single case or several cases according to (Yin, 2015). The maintenance practice of buildings are varies based on the requirements. As a result, the study is intended to study five cases of commercial buildings practicing the MB. Therefore, the analysis of the MB practice was performed in multiple case studies. Considering the nature of the study, it is essential to collect detailed information from the maintenance professionals. As a result, the qualitative method was selected. A comprehensive literature review of the maintenance and MB of buildings was conducted initially. In addition, current practices and MB components, and MB barriers have been identified. To continue this study, the case study was selected as the most appropriate approach for this research because the in-depth analysis is most important to analyse the MB practice in a commercial building to identify the issues related to MB practice. Profiles of the selected cases are summarised in Table 1

\begin{tabular}{|l|l|l|l|l|}
\hline \multirow{2}{*}{ Cases } & \multicolumn{4}{|c|}{ Building information } \\
\cline { 2 - 5 } & Type of business & $\begin{array}{l}\text { Gross floor } \\
\text { area (sq. Ft.) }\end{array}$ & $\begin{array}{l}\text { Number of } \\
\text { floors }\end{array}$ & $\begin{array}{l}\text { Expected } \\
\text { lifetime }\end{array}$ \\
\hline A & Commercial & 538,196 & $39 * 2$ & 100 years \\
\hline B & Banking & 500,000 & 22 & 50 years \\
\hline C & Banking & 500,000 & 32 & 35 years \\
\hline D & Office & 70,000 & 8 & 60 years \\
\hline E & Commercial & 350,000 & 13 & 100 years \\
\hline
\end{tabular}

Table 1 Case Profile

The cases were restricted to five commercial buildings that currently practicing maintenance budgets because the selection of cases was constrained by limited accessibility due to this pandemic and lack of MB practices because there is no separate budget practice for building maintenance in Sri Lankan commercial buildings.

Semi-structured interviews were conducted to verify the barriers in MB practices. Further, the strategies to overcome the barriers have been identified which could not find in the literature. The current practice of $\mathrm{MB}$, key considerations, and MB components identified in the literature review was validated and modified by an expert in the maintenance field. The profile of interview participants of selected cases is summarised in Table 2. 


\begin{tabular}{|l|c|l|}
\hline Cases & Respondent & Designation \\
\hline A & A1 & General Manager - Facilities Management \\
\hline B & A2 & Maintenance manager \\
\hline B1 & Senior Manager - Facilities Management \\
\hline C & B2 & Maintenance executive \\
\hline D & C1 & Engineer \\
\hline E & D1 & Maintenance manager \\
\hline & D2 & Macility Manager \\
\hline & E1 & Facility Manager \\
\hline
\end{tabular}

Table 2 Profile of interview participants of selected cases

Respondents were selected based on their knowledge of maintenance cost panning. we planned to get three responses from each case. However, two respondents were selected from each case because of the current pandemic situation of the country. Data were analysed through manual analysis and content analysis with aid of NVivo 12 software. Under the manual analysis, the current practice of MB, a key consideration of MB preparation, and components of MB were analysed via cross-case analysis. Barriers and the strategies to overcome the barriers were analysed via the content analysis.

\section{Research findings and discussion}

In current practice, in most of the buildings, there is a large deviation between the actual and the projected MB. To evident that, the deviation between the actual and projected budget for the last three years of selected five cases were analysed. The deviation (in percentage) is illustrated in Figure 2

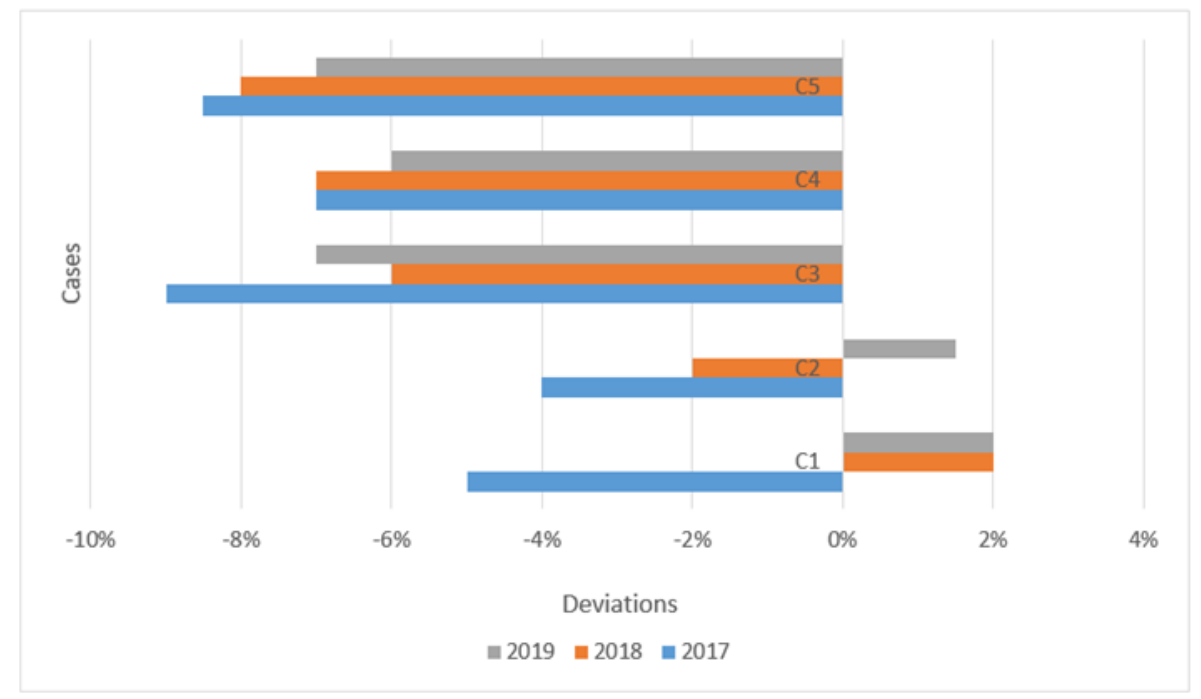

Figure 2 deviation between the actual and projected budget

Regarding the findings, all the cases indicated the deviation between the actual and projected budget. However, in most cases, actual budgets were negatively deviating from the projected budgets. According to the literature found, to achieve effective maintenance, budgets should be defined correctly through the proper budget method and the maintenance strategy (Mohd-Noor et al., 2011). Therefore, it is important to have a detailed and informative MB to project an accurate MB. However, based on the finding, there were different types of budgeting practices in current industrial practice in Sri Lankan commercial buildings. Most of the cases practice the historical-based MB rather than using the detailed MB. In this budget, spending for the projected period is adjusted, depending on the previous period's result and on the expectations for the projected period (Lai, 2010). According to the interviewees, the budgets for the cases where the historical-based MB was used are considerably negatively deviating. Further, It is important to develop a combination of different maintenance strategies to properly maintain the systems and to ensure 
that they remain in order and minimise asset downtime and repair costs (CEN EN 13306, 2001). However, based on the discussion with selected cases, only one case practiced the predictive, preventive, conditioned-based maintenance strategies and others were practiced preventive and reactive maintenance strategies. Thus, it is evident that many cases deviate negatively according to the Figure 2.

Moreover, it is important to identify the key considerations that affect the MB due to budget preparation to avoid inaccurate maintenance cost planning. Demand for the maintenance, issues that facing when to perform the maintenance works, prioritisation of maintenance works, records, and maintenance strategies as key considerations that need to consider to prepare the MB. Therefore, the finding revealed that the demand for maintenance increases due to ageing, usage, the impact of external factors, occupant attitude and behavior, sudden breakdown, the performance of the assets, and requests from top management. Prioritization of asset replacement is a method that incorporates the operation of all aspects of an organisation to better maximise how they spend time, money and resources on maintaining infrastructure assets at the center of asset replacement over their entire life cycle. to ensure the activities that optimise the return on investment are carried out, activities for the maintenance of production assets need to be prioritised. However, in the Sri Lankan context, there is a lack of asset prioritisation in building maintenance.

\begin{tabular}{|c|c|c|}
\hline \multirow[t]{2}{*}{ Cases } & \multicolumn{2}{|c|}{ Having asset prioritisation } \\
\hline & Yes & No \\
\hline Case 1 & $\sqrt{ }$ & \\
\hline Case 2 & $\sqrt{ }$ & \\
\hline Case 3 & & $\sqrt{ }$ \\
\hline Case 4 & & $\sqrt{ }$ \\
\hline Case 5 & & $\sqrt{ }$ \\
\hline
\end{tabular}

Table 3 asset prioritisation in building maintenance

Based on the discussion with respondents, it shows that only two cases were practiced the assets prioritisation while carrying out the maintenance activities who faced the inadequate budgeting problem.

\begin{tabular}{|c|c|c|}
\hline (†) Name & $\Delta$ Files & References \\
\hline$\square \bigcirc \quad$ Barriers & 10 & 108 \\
\hline$\square$ Environmental Factors & 10 & 29 \\
\hline Changes in country market condition & 10 & 17 \\
\hline O Unqualified Maintenance contractors & 8 & 10 \\
\hline O Financial Factors & 10 & 17 \\
\hline Poor financial control when executing maintenance work & 7 & 7 \\
\hline Poor Financial Support for Maintenance Work & 10 & 11 \\
\hline$\square \bigcirc$ Managerial Factors & 10 & 37 \\
\hline Inadequate past records & 6 & 6 \\
\hline No right budgeting method & 5 & 6 \\
\hline Poor maintenance policy and strategy & 6 & 6 \\
\hline Poor planning of maintenance works and resources & 10 & 11 \\
\hline O Unavailability of skill labours & 8 & 8 \\
\hline$\square$ Social Factors & 10 & 14 \\
\hline Cultural practice & 6 & 6 \\
\hline O Poor occupants behaviour & 8 & 8 \\
\hline - $O$ Technical Factors & 10 & 26 \\
\hline O Design Problem & 8 & 9 \\
\hline O Faulty Maintenance & 10 & 13 \\
\hline O Poor Quality Control & 5 & 5 \\
\hline
\end{tabular}

Figure 3 Barriers of MB preparation 


\subsection{BARRIERS OF MB PRACTICE}

In terms of the factors that influence maintenance expenses, the problems that occur when planning a MB for commercial buildings in Sri Lanka have been discussed. The major factors are technical, managerial, financial, environmental and social factors. Figure 3 shows the Identified barriers under major factors were analysis via the codebase analysis with the aid of NVivo 12 software.

According to this codebase analysis of the barriers of MB preparation, changes in market condition, poor financial support, poor planning of maintenance works and resources and faulty maintenance are the key barriers of the MB practice identified via the case studies. Further, unqualified maintenance contractors, design problems, unqualified skill labours, and poor occupant's behavior are indicated by most of the respondents. Moreover, there were other issues mentioned in the above figure.

\subsection{STRATEGIES TO OVERCOME THE BARRIERS OF MB PRACTICE}

Strategies to enhance the accuracy of the MB in commercial buildings were gathered through the opinions of the respondents and analysed. The coding structure which was developed using NVivo 12 software is presented in Figure 4.

\begin{tabular}{|c|c|c|c|}
\hline \multirow{2}{*}{$\begin{array}{r}\oplus \\
\square 0\end{array}$} & ame & Files & References \\
\hline & rategies to overcome the barriers & 10 & 83 \\
\hline $\mathrm{O}$ & Update in government rules and regulations & 7 & 7 \\
\hline O & Select right budgeting method & 10 & 14 \\
\hline $\mathrm{O}$ & Quality control & 8 & 10 \\
\hline $\mathrm{O}$ & Maintain past recodes & 10 & 12 \\
\hline $\mathrm{O}$ & Effective design & 6 & 6 \\
\hline O & Avoid the faulty maintenance & 10 & 11 \\
\hline $\mathrm{O}$ & Assign skill and experience personal & 9 & 10 \\
\hline $\mathrm{O}$ & Arise awareness of top management & 10 & 13 \\
\hline $\mathrm{O}$ & Arise awareness and security control & 7 & 7 \\
\hline $\mathrm{O}$ & Adapt with combination of different strategies & 5 & 6 \\
\hline
\end{tabular}

Figure 4 Strategies to overcome the barriers

Avoid fault in maintenance, arise awareness of top management, select an appropriate budget method and maintaining the records properly are the major strategies indicated via the case study. Further, quality control, assigning skill and experienced personals, arise awareness, and security control are also the strategies that help to overcome those barriers of MB preparation. Moreover, effective design, updated market conditions, and government regulations are the strategies proposed by the participants to mitigate the prevailing barriers.

\subsection{FRAMEWORK}

The research aims to develop a framework to enhance the practice of a well-defined MB for commercial buildings in Sri Lanka. The framework includes key considerations that need to consider while preparing the MB, maintenance strategies, and the right budget method that needs to choose to project the adequate expenditure to perform the maintenance work effectively. Further, the framework includes significant barriers and strategies to overcome those aforementioned barriers to define the budget appropriately. 


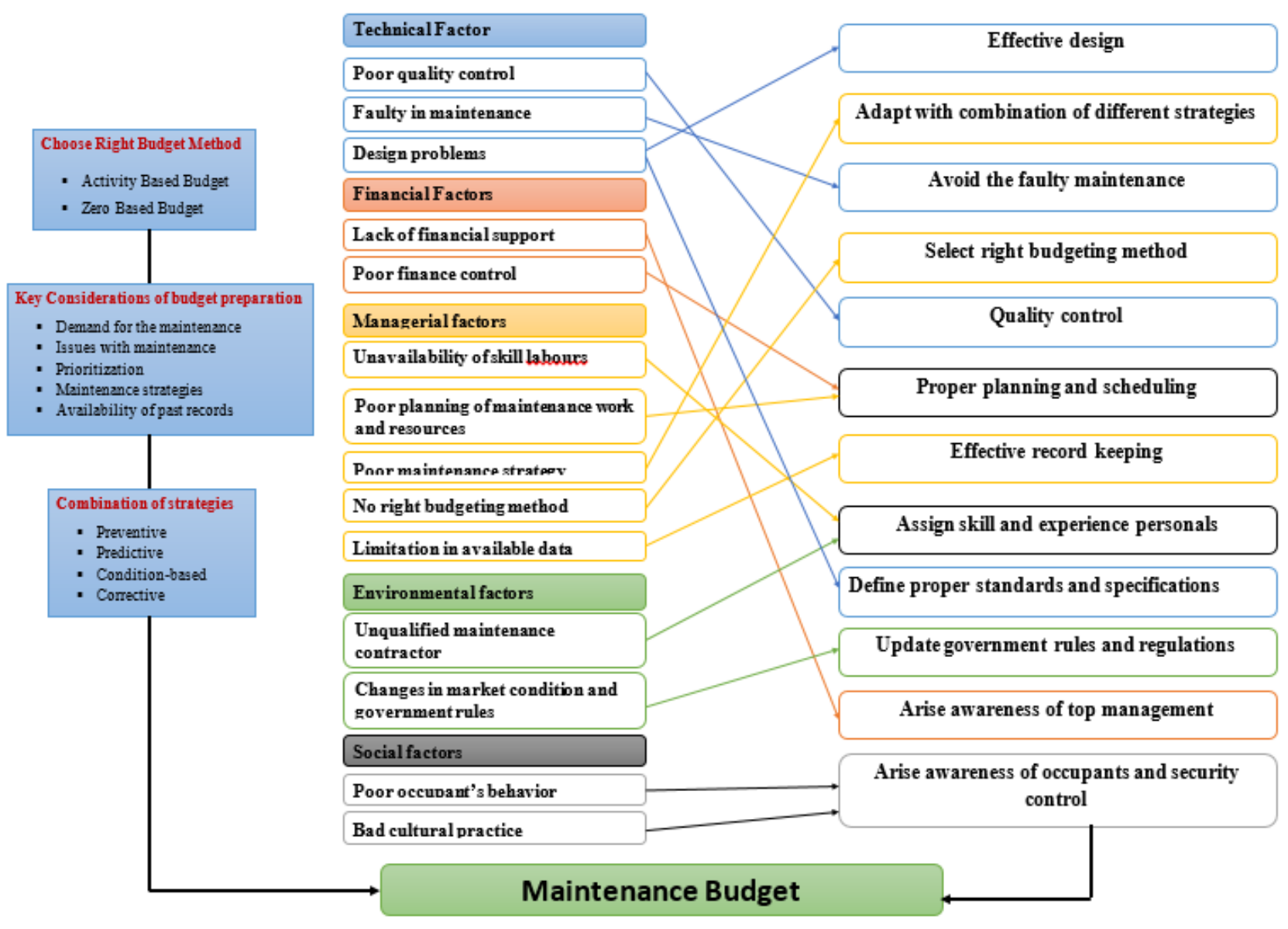

Figure 5 framework

\section{Conclusions and recommendations}

It was identified that most of the maintenance budgets in commercial buildings are underestimated compared to the actual amount. Estimating the MB of a plant system is a critical administrative choice that has traditionally been relied on non-scientific methods such as historical data, expert views, assuming it as a percentage of the capital cost, and so on. There are no scientific recommendations for such a key operational choice, according to the literature. Hence, a detailed and appropriate budget method is required to improve the accurate MB preparation. Based on the analysis of the case study as well as literature findings, Zero-based and Activity-based MB methods are informative and better methods compared to the conventional (Historical) MB method. However, an appropriate method of budget preparation is not practiced by building practitioners in the Sri Lankan context. The historical-based budgeting practice predominates between a variety of budgeting. Lack of financial support, poor planning of maintenance work, faulty maintenance, market condition of the country, and poor occupant behavior were identified as major barriers that affect the accuracy of the MB. Hens, selecting the right budget method, arise awareness of management, always keeping in touch with government rules and regulations and better planning of maintenance works are the key strategies to overcome the key barriers prevailing in the commercial building sector. Developed strategies can be followed to overcome the barriers of MB practice to increase the accuracy of estimating the MB and effectiveness of maintenance works. Finally, a framework was developed, integrating by recognising the basic aspects of MB preparation, respective barriers of accurate budget preparation, and respective strategies to overcome those barriers. Hence, accurate MB preparation is vital to get enough funds that will avoid the shortage of spending and the negative deviation between projected and actual expenditure.

Contribution to knowledge: This research mainly focused on enhancing the practice of appropriate MB in commercial buildings in Sri Lanka. The results of the research can be used in the following ways to enhance knowledge.

- Understanding the concept of maintenance and Maintenance budgeting and its components. 
- Understanding the current practices of Maintenance budgeting in a commercial building in Sri Lanka.

- Understating the key consideration that needs to consider when preparing the MB.

- Comprehension of the barriers regarding inaccurate Maintenance budgeting practice and identifying the respective strategies.

\section{References}

Bernama (2019) Insufficient funding reason for backlog of maintenance on federal roads. Available at: https://www.nst.com.my/news/nation/2019/03/467023/insufficient-funding-reason-backlogmaintenance-federal-roads.

Booty, F. (2009) Facilities Management Handbook. 4th edn. Routledge.

British Standards (BS EN 13306) (2017) Maintenance - Maintenance terminology.

British Standards 8210 (2012) Guide to facilities maintenance management. London: British Standards Institution.

CEN (European Committee for Standardization) EN 13306 (2001) Maintenance terminology.

Chartered Institute of Management Accountants (CIMA) (2008) Budgeting. United Kingdom: Louise Ross and Technical Information Service.

Che-Ghani, N. Z., Myeda, N. E. and Ali, A. S. (2016) ‘Operations and Maintenance Cost for Stratified Buildings: A Critical Review', MATEC Web of Conferences, 66. doi: 10.1051/matecconf/20166600041.

Chen, C. and Tang, L. (2019) 'BIM-based integrated management workflow design for schedule and cost planning of building fabric maintenance', Automation in Construction. Elsevier, 107(September), p. 102944. doi: 10.1016/j.autcon.2019.102944.

Chitra, T. (2003) 'Life based maintenance policy for minimum cost', in Annual RELIABILITY AND MAINTAINABILITY Symposium, pp. 470-474. doi: 10.1109/RAMS.2003.1182034.

Dhillon, B. S. (2002) Engineering Maintenance A Modern Approach. 1st edn. CRC Press.

Ekim, H. and Ekim, M. (2016) 'The cause and effects of neonatal/infantile thymectomy', Medical Journal of Dr. D.Y.

Patil University, 9(1), pp. 148-149. doi: 10.4103/0975-2870.167996.

Faremi, O., Adenuga, O. and John, B. (2014) 'Factors affecting maintenance cost of institutional buildings', The Mathematical Gazette, 55(393), pp. 298-305. doi: 10.2307/3615019.

Gupta, P., Gupta, S. and Gandhi, O. P. (2014) 'Annual maintenance budget estimation for a plant system: Digraph model and matrix approach', Journal of Quality in Maintenance Engineering, 20(2), pp. 193-210. doi: 10.1108/JQME-04-2013-0015.

Ihsan, B. (2017) Factors Affecting Operation and Maintenance Cost of Hotels in Saudi Arabia. Dhahran: College of Environmental Design. University of Petroleum \& Minerals, Dhahran.

Ihsan, B. and Alshibani, A. (2018) 'Factors affecting operation and maintenance cost of hotels', Property Management, 36(3), pp. 296-313. doi: 10.1108/PM-04-2017-0023.

Krstic, Hrvoje; Marenjak, S. (2017) 'Maintenance and operation costs model for university buildings', Model procjene troskova odrzavanja i uporabe sveucilisnih građevina, pp. 193-200. doi: 10.17559/TV-20140606093626.

Lai, J. H. K. (2010) 'Operation and Maintenance budgeting for commercial buildings in Hong Kong', Construction Management and Economics, 28(4), pp. 415-427. doi: 10.1080/01446190903365665.

Le, A. T. H. et al. (2018) 'Building maintenance cost planning and estimating: A literature review', in Proceeding of the 34th Annual ARCOM Conference, ARCOM 2018, pp. 697-706.

Lee, H. and Scott, D. (2008) 'Development of a Conceptual Framework for the Study of Building Maintenance Operation Processes in the Context of Facility Management', Surveying and Built Environment, 19(1), pp. 81101.

Lennerts, K. and Bahr, C. (2008) 'CIBW 70 International Conference in Facility Management Achieving Healthy and Creative Facilities Department for Facility Management, Universität Karlsruhe ( TH ), Germany', in.

Lind, H. and Muyingo, H. (2012) 'Building maintenance strategies: Planning under uncertainty', Property Management, 30(1), pp. 14-28. doi: 10.1108/02637471211198152.

McNair, S. (2011) 'Budgeting for Maintenance: A Behavior-Based Approach.', Life Cycle Engineering. Available at: www.LCE.com

Mohd-Noor, N. et al. (2011) 'Building maintenance budget determination: An exploration study in the Malaysia government practice', Procedia Engineering, 20(December), pp. 435-444. doi: 10.1016/j.proeng.2011.11.186.

Muchiri, P. et al. (2011) 'Development of maintenance function performance measurement framework and indicators', International Journal of Production Economics. Elsevier, 131(1), pp. 295-302. doi: 10.1016/j.ijpe.2010.04.039.

NSW Heritage Office (2014) Preparing a Maintenance Plan. Available at: https://www.environment.nsw.gov.au/research-and-publications/publications-search/preparing-amaintenanceplan-information-sheet-1-1. 
Nuratirah, S., Nasir, C. M. and Aziz, S. (2018) 'Performance of Building Maintenance in Operation \& Management At Commercial Building', International Journal of Modern Trends in Business Research (IJMTBR), 1(5), pp. 26008742.

Ojua, M. O. (2016) 'The Importance of Budget and Budgetary Process among Non-Publicly Accountable Entities (NPAEs): A Survey of Micro Sized Firms in Nigeria', The International Journal of Business and Management, 4(7), pp. 305-312. Available at: www.theijbm.com.

Perera, B. A. K. S. et al. (2016) 'Determinants of operational and maintenance costs of condominiums', BuiltEnvironment Sri Lanka, 12(1), p. 24. doi: 10.4038/besl.v12i1.7613.

Schuh, G., Jussen, P. and Optehostert, F. (2019) 'Iterative cost assessment of maintenance services', Procedia CIRP. Elsevier B.V., 80, pp. 488-493. doi: 10.1016/j.procir.2019.01.067.

Sharma, G., Kumar, A. and Jain, M. (2002) 'Maintenance Cost Analysis for Replacement Model With Perfect Minimal Repair', International Journal of Engineering, 15(2), pp. 161-168.

Sondalini, M. (2000) The Cost of Maintenance Destroys Your Capital Investment Returns. Available at: https://accendoreliability.com/cost-maintenance-destroys-capital-investment-returns/.

Srivastava, A. K., Kumar, G. and Gupta, P. (2020) 'Estimating maintenance budget using Monte Carlo simulation', Life Cycle Reliability and Safety Engineering. Springer Singapore, 9(1), pp. 77-89. doi: 10.1007/s41872-02000110-7.

Steiner, R. and Kaiser, C. (2016) 'Top-down versus bottom-up : comparing amalgamation strategies in Europe Claire Kaiser and Reto Steiner Top-down versus bottom-up : comparing amalgamation strategies in Europe Paper presented at the XVI International Research Society for Public Management', (January 2012).

Straub, A. (2012) Maintenance and repair, International Encyclopedia of Housing and Home. Elsevier Ltd. doi: 10.1016/B978-0-08-047163-1.00523-3.

Suffian, A. (2013) 'Some common maintenance problems and building defects: Our experiences', Procedia Engineering. Elsevier B.V., 54, pp. 101-108. doi: 10.1016/j.proeng.2013.03.009.

Velmurugan, R. S. and Dhingra, T. (2015) 'Maintenance strategy selection and its impact in maintenance function: A conceptual framework', International Journal of Operations and Production Management, 35(12), pp. 16221661. doi: 10.1108/IJOPM-01-2014-0028.

Weerasinghe, A., Ramachandra, T. and Rotimi, J. O. B. (2016) 'A Simplified model for predicting running cost of office buildings in Sri Lanka', Proceedings of the 32nd Annual ARCOM Conference, ARCOM 2016, (May), pp. 331-340.

Wickern, V. M. Z. (2019) 'Challenges and Reliability of Predictive Maintenance', 'Rhein-Waal University Of Applied Sciences ...', nan(March), p. nan. doi: 10.13140/RG.2.2.35379.89129.

Zakiyudin, M. Z. et al. (2019) 'The User Requirements for Building Maintenance Management Systems in Malaysian Public Universities', IOP Conference Series: Materials Science and Engineering, 620(1). doi: 10.1088/1757899X/620/1/012076. 